\title{
Ossiculoplasty Using Preserved Septal Cartilage
}

\author{
Kartik Irappa Patil ${ }^{1}$, Rukmini M Prabhu ${ }^{2 *}$, Bharath Kanna Karunakaran ${ }^{3}$, Nikitha R $^{4}$, Rinki J Pomson ${ }^{5}$ and \\ BorlingegowdaViswanatha ${ }^{6}$
}

${ }^{1,2}$ Senior residents, Department of ENT, Bangalore Medical College\& Research Institute, India

3,4,5 Postgraduate, Department of ENT, Bangalore Medical College\& Research Institute, India

${ }^{6}$ Professor and Head, Department of ENT, Bangalore Medical College\& Research Institute, India

*Corresponding author: Rukmini M Prabhu, Senior Resident, Department of ENT, Bangalore Medical College\& Research Institute, Bangalore, India

\begin{abstract}
Ossicular chain reconstruction is the primary method of restoring conductive hearing deficit seen in chronic middle ear disease. Many factors affect outcomes in this procedure including the middle ear environment, status of the Eustachian tube, surgical technique, type of prosthesis and status of residual ossicular remnants. Many materials have been used for Ossiculoplasty including both biologic and alloplastic materials, with varying degrees of success. This study was done to evaluate the efficacy of preserved septal cartilage as ossicular reconstruction prosthesis in patients with mucosal type of COM (chronic otitis media) with ossicular discontinuity.

Objective: To evaluate the efficacy of preserved septal cartilage as ossicular reconstruction prosthesis in patients with mucosal type of COM with ossicular discontinuity.

Materials and Methods: A prospective study of 20 patients with mucosal type of COM, undergoing Ossiculoplasty was conducted at a teaching tertiary care hospital from January 2019 to July 2020.

Results: A total 20 patients (13 males and 7 females) between the age group of 18-60 years with mucosal type of COM with ossicular discontinuity were included in the study. Out of 20 patients 18 patients (90\%) had improvement in A-B gap (air bone gap) after surgery and 2 patients had no improvement in A-B gap after 3 months of follow up. The mean hearing gain was $12.25 \pm 7.23 \mathrm{~dB}$ which was statistically significant ( $p$ value 0.001 ).

Conclusion: Preserved septal cartilage is a good material for ossicular reconstruction in terms of postoperative hearing improvement and closure of A-B gap. By giving careful attention to the principles of ossicular construction and understanding basic principles and applying them in clinical practice, it is possible to give more desirable hearing results for the patients.
\end{abstract}

Keywords: Ossiculoplasty, septal cartilage

Abbreviations: COM: Chronic Otitis Media

\section{Introduction}

Chronic otitis media (COM) is the presence of irreversible inflammatory disease in the middle ear cleft. It also affects the ossicular chain leading to conductive hearing loss. Erosion of the ossicular chain is seen in about $80 \%$ of patients who present with chronic otitis media with cholesteatoma whereas it is present in approximately $20 \%$ COM cases without cholesteatoma. Incus is the most frequently affected ossicle, followed by the stapes and malleus [1]. Ossicular chain reconstruction is the primary method of restoring conductive hearing deficit seen in chronic middle ear disease [2,3].Many factors affect outcomes in this procedure including the middle ear environment, status of the Eustachian tube, surgical technique, type of prosthesis and status of residual 
ossicular remnants [4,5]. Austin classified ossicular chain disruption into 4 groups (ABC\&D) based on the presence or absence of the malleus handle and the stapes arch. Kartush added three more categories to this classification: intact ossicular chain (0), fixation of the malleus head (E) and fixation of the stapes (F) [6]. Many materials have been used for Ossiculoplasty including both biologic and alloplastic materials, with varying degrees of success. Ideally, the reconstruction material should be biocompatible, safe, easy to fit and handle, and capable of efficient sound transmission. Biologic materials like autograft or homograft ossicles, cortical bone, teeth, and cartilage have been used. Body of Incus often reshaped, is the most common auto graft used as ossicular prosthesis [7]. This study was done to evaluate the efficacy of preserved septal cartilage as ossicular reconstruction prosthesis in patients with mucosal type of COM with ossicular discontinuity.

\section{Material and Methods}

A prospective study of 20 patients with mucosal type of COM, undergoing Ossiculoplasty was conducted at a teaching tertiary care hospital from January 2019 to July 2020.

\section{Inclusion criteria were}

a) Patients in the age group 18-60 years

b) Patients with inactive mucosal type of COM with ossicular discontinuity

c) Patients with only conductive hearing loss

d) Patients with intact stapes superstructure.

e) Patients with intact Eustachian tube function.

\section{Exclusion criteria were}

a) Patients $<18$ years and $>60$ years

b) Patients with squamosal type of COM

c) Patients with active mucosal type of COM

d) Patients with sensorineural hearing loss

e) Patients with revision surgeries

f) Patients with stapes erosion.

g) Patients with Eustachian tube dysfunction.

Routine otorhinolaryngological examination was done to rule out any septic foci. Tuning fork test was done using $512 \mathrm{~Hz}$ tuning fork. Severity of hearing loss was done by pure tone audiometry. Audiometric testing was done in double-walled sound protective rooms with standard procedures. Preoperative audiometric testing was performed at 500, 1000, 2000 and $3000 \mathrm{~Hz}$. Postoperative air- and bone-conduction scores were recorded at 500, 1000, 2000 and $3000 \mathrm{~Hz}$. Preoperative and perioperative findings noted were status of tympanic membrane, ossicles and attic, presence of cholesteatoma. Patients underwent tympanoplasty with ossicular reconstruction by post auricular approach. 14 patients underwent surgery under local anesthesia and 6 patients underwent surgery under general anaesthesia. Mastoidectomy was not performed in any patients since the patients in study group had dry ear in inactive stage. Preserved septal cartilage taken from septal surgeries which was stored in diluted isopropyl alcohol was used for ossicular reconstruction. The cartilage was properly sculpted and placed over the stapes head. Temporalis fascia was placed between the prosthesis and tympanic membrane remnant (Graph 1). Postoperative hearing assessment was done by pure tone audiometry at 12 weeks after surgery. Results were analyzed statistically.

\section{Results}

A total 20 patients (13 males and 7 females) between the age group 18-60 years with mucosal type of COM with ossicular discontinuity underwent tympanoplasty with ossicular reconstruction (Table 1, Graph 2). Out of 20 patients 4 patients were diabetic and others had no comorbidities. Out of 20 patients 13 patients had an average preoperative air-bone gap (A-B gap) between $25-35 \mathrm{~dB}$ and 7 patients had an average preoperative A-B gap between 35-45dB (Tables 2 \&3, Graph 3). 18 patients had improvement in A-B gap after surgery and 2 patients had no improvement in A-B gap after 3 months of follow up (Table 4, Graph 4). Majority of patients had improvement in A-B gap between $1-10 \mathrm{~dB}$. The mean hearing gain was $12.25 \pm 7.23 \mathrm{~dB}$ which was statistically significant ( $\mathrm{p}$ value 0.001 ) (Table 5 ). There were no intraoperative (bleeding, facial nerve palsy, chorda tympani nerve injury, wound hematoma) and postoperative complications (infections, bleeding, wound gaping, facial paralysis perichondritis, epithelial pearl formation, granulation tissue formation at the tympan meatal flap or sensorineural hearing loss) noted in the study group.

Table 1: No. of patients in study group according to age.

\begin{tabular}{|c|c|c|c|}
\hline Age in Years & No. of Males & No. of Females & Total \\
\hline $18-20$ & 1 & 0 & 1 \\
\hline $21-30$ & 2 & 2 & 4 \\
\hline $31-40$ & 5 & 4 & 9 \\
\hline $41-50$ & 3 & 1 & 4 \\
\hline $51-60$ & 2 & 0 & 2 \\
\hline Total & 13 & 7 & 20 \\
\hline
\end{tabular}

Table 2: Tympanic membrane perforation distribution in study group.

\begin{tabular}{|c|c|c|c|}
\hline $\begin{array}{c}\text { Perforation } \\
\text { Size }\end{array}$ & $\begin{array}{c}\text { Right (No. of } \\
\text { Patients) }\end{array}$ & $\begin{array}{c}\text { Left (No. of } \\
\text { Patients) }\end{array}$ & Total \\
\hline Small central & 3 & 2 & 5 \\
\hline Large central & 6 & 5 & 11 \\
\hline Subtotal & 3 & 1 & 4 \\
\hline Total & 12 & 8 & 20 \\
\hline
\end{tabular}


Table 3: Ossicular erosion in patients.

\begin{tabular}{|c|c|}
\hline Ossicular Erosion & No. of Patients \\
\hline Incus (partial) & 11 \\
\hline Incus (complete) & 5 \\
\hline Malleus and Incus (complete) & 4 \\
\hline
\end{tabular}

Table 4: Postoperative hearing gain in study group.

\begin{tabular}{|c|c|c|}
\hline Hearing Gain & No. of Patients & Percentage \% \\
\hline $0 \mathrm{~dB}$ & 2 & 10 \\
\hline $1-10 \mathrm{~dB}$ & 8 & 30 \\
\hline $11-20 \mathrm{~dB}$ & 7 & 15 \\
\hline$>20 \mathrm{~dB}$ & 3 & 100 \\
\hline Total & 20 & 15 \\
\hline
\end{tabular}

Table 5: Comparison of Pre and Postoperative 3 Months Hearing.

\begin{tabular}{|c|c|c|c|}
\hline AB Gap & Mean & Standard Deviation & 5.51 \\
\hline Pre & $34.40 \pm 5.51$ & 2.17 & 0 \\
\hline Post 3 Months & $22.15 \pm 2.17$ & 7.23 & \\
\hline Difference & $12.25 \pm 7.23$ & \\
\hline
\end{tabular}

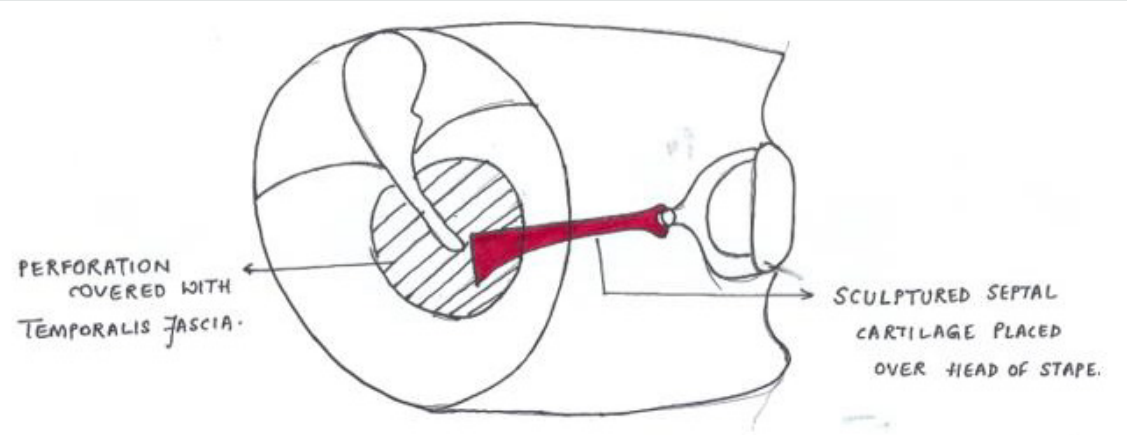

Figure 1: Showing diagrammatic picture of Ossiculoplasty.

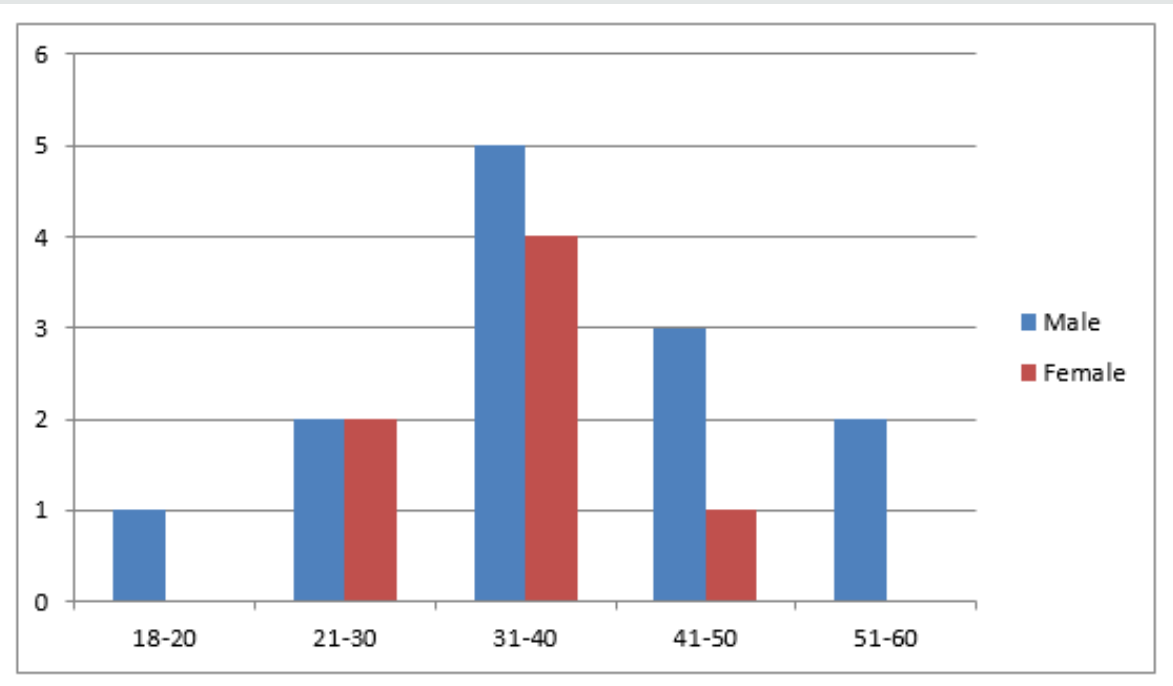

Figure 2: Age distribution of patients studied. 


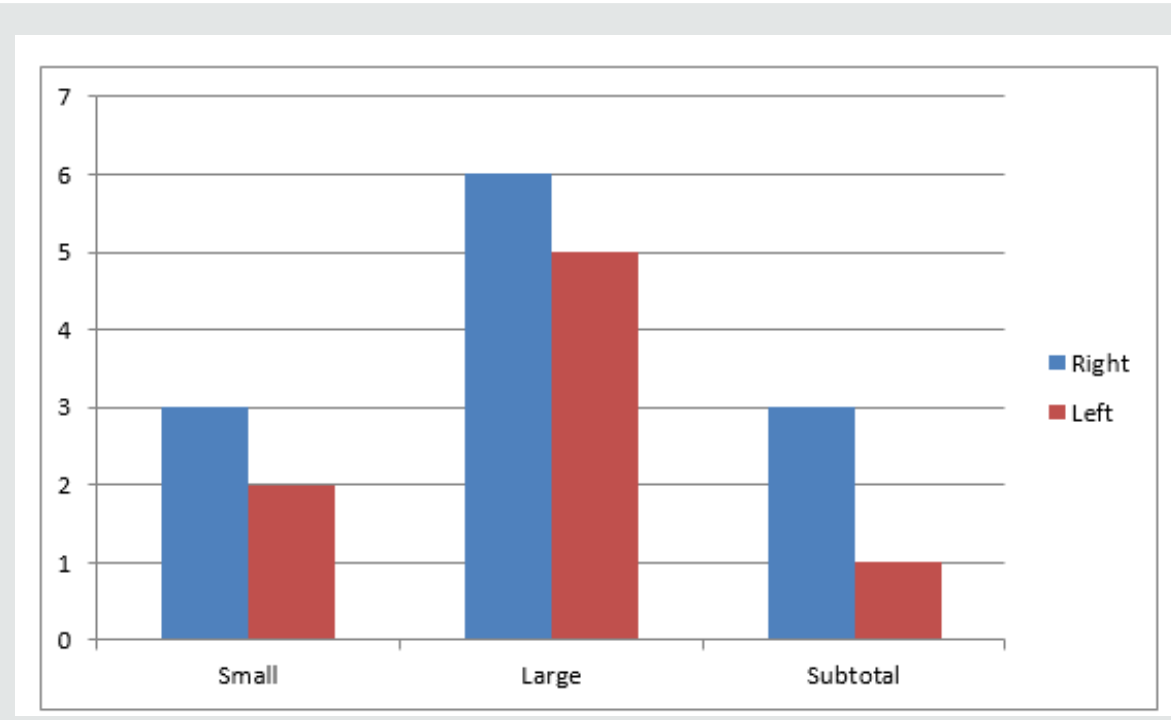

Figure 3: Tympanic membrane perforation distribution in study group.

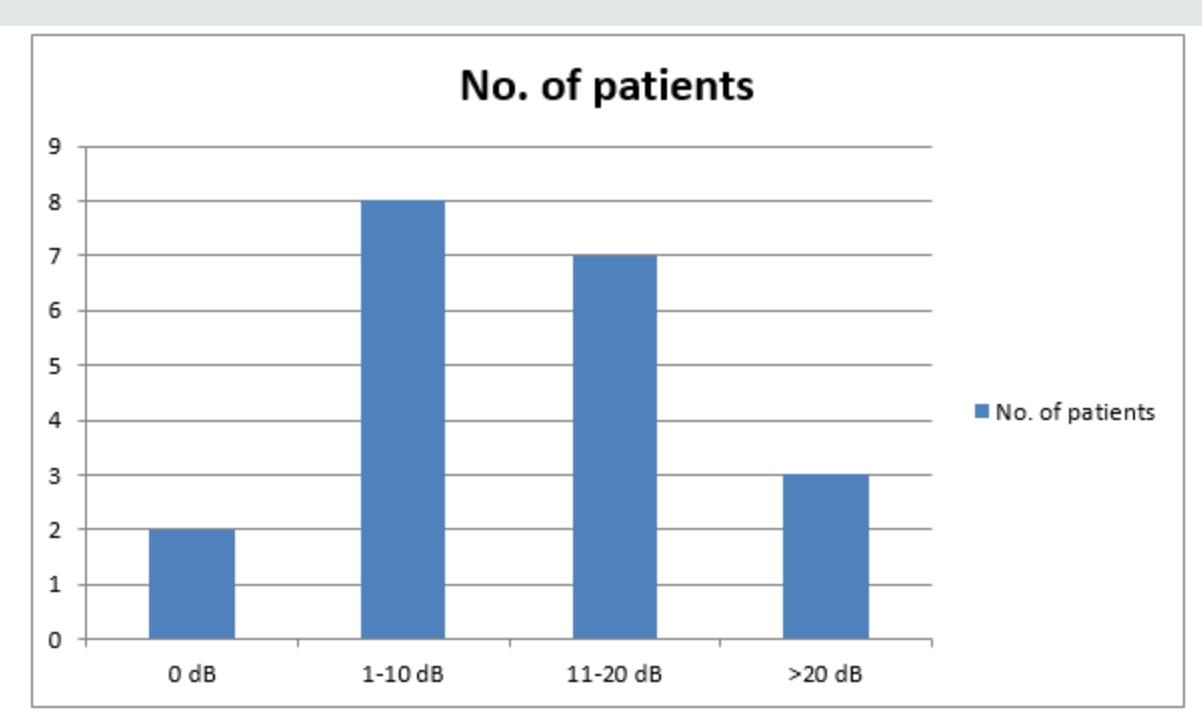

Figure 4: Postoperative hearing gain in study group.

\section{Discussion}

The objective of the tympanoplasty is to provide a dry ear, ensure the function of Eustachian tube, and restore the soundconducting system of the middle ear. Ossicular chain reconstruction is a challenging procedure even for experienced otologists and the success is achieved with good and long-lasting audiometric outcome, represented by closure of postoperative A-B gap less or equal do $20 \mathrm{~dB}[4,8]$. We observed an improvement of a mean $12.25 \mathrm{~dB}$ in postoperative speech reception thresholds. The mean A-B gap before surgery was $34.40 \mathrm{~dB}$ and decreased to $22.15 \mathrm{~dB}$ after reconstruction, showing an improvement of $12.25 \mathrm{~dB}$. For an ideal reconstruction, procedure should be easy to perform and the materials should be well tolerated by the patient, with low reabsorption or extrusion rates, and it should provide good hearing results over the time. Many of materials are used for ossicular reconstruction, i.e. autografts (autologous incus, tragal cartilage, and cortical bone), bone cement or prosthesis. The autograft materials are a good alternative because of the biocompatibility, low extrusion rate, and their lower price compared with other groups of prosthesis. Emir et al. reported a success rate of $58.1 \%$ using autologous incus and $71.4 \%$ using cortical bone [9]. OConnel et al., in a study of 156 patients who underwent ossiculoplasty with titanium prosthesis, showed that $67 \%$ of the patients achieved A-B gap $\leq 20 \mathrm{~dB}$ and the majority of the reconstructions were with tragal cartilage, achieving $72.3 \%$ of success [10]. We used preserved septal cartilage in the presence of the stapes superstructure, 
placing it between the stapes head and handle of malleus. We achieved $90 \%$ hearing improvement after surgery with3 patients (15\%) showing closure of A-B gap $<20 \mathrm{~dB}$. The variability in the literature concerning hearing results after ossiculoplasty is due to a lack of understanding and uniform reporting of middle ear factors that influence the results. The factors that influence successful hearing results after ossiculoplasty include the presence of a stapes superstructure, the presence of a malleus handle, the status of the middle ear mucosa, perforation of the tympanic membrane, the presence of cholesteatoma, the type of prosthesis, Eustachian tube function and revision surgery $[11,12]$. Out of these, the presence of a malleus handle, the presence of a stapes superstructure and the status of the middle ear mucosa, have been found to be most important [11-13]. Mills in his study reported that the loss of the stapes arch was a significant factor causing worse outcome, but only 55 ossiculoplasty were analyzed [14]. Albuetal studied prognostic factors in 544 patients who underwent ossiculoplasty and concluded that the presence of the malleus handle and the mucosal status were the most important predictors [15]. Dornhoffer and Gardnerin their study of 200 ossiculoplasties concluded that mucosal status, presence of the malleus handle, otorrhea, mastoidectomy, and revision surgery were significant prognostic factors [14]. Yung and Vowler studied the long-term outcomes of 145ossiculoplasties and concluded that the presence of the malleus handle was the only significant factor [11]. In our patient series, middle ear mucosa was healthy and the stapes suprastructure was present in all the patients explaining a good success rate $(90 \%)$ and hence proved to be the most significant prognostic factors for successful ossiculoplasties.

\section{Conclusion}

Ossicular reconstruction still remains a challenging procedure. The outcome of surgery depends on many prognostic factors. In our study we obtained surgical success in $90 \%$ of surgeries. The presence of the stapes superstructure and normal middle ear mucosa were significant predictive factors for successful results after ossiculoplasty. With the continuing advances in the understanding of middle ear mechanics, the outcome of ossiculoplasty is improving. By giving careful attention to the principles of ossicular construction and understanding basic principles and applying them in clinical practice, it is possible to give more desirable hearing results for the patients.

\section{References}

1. Dornelles C, Rosito LPS, Meurer L, da Costa SS, Argenta A, et al. (2007) Correlation of the ossicular chain in the intraoperative with histological findings of cholesteatomas. Braz J Otorhinolaryngol 73: 738-743.

2. Statistics ABO (1993) Disability, Ageing and Cares. Hearing Impairment.

3. Hogan A, Shipley M, Strazdins L (2001) Communication and behavioral disorders among children with hearing loss increased risk of mental health disorders. . Australian \& NZ Journal of Public Health 35(4): 377 383 .

4. Cox MD, Trinidade A, Russell JS, Dornhoffer JL (2017) Long-term hearing results after ossiculoplasty. Otol Neurotol 38: 510-515.

5. Castro SA, Henriques V, Rodrigues J, Fonseca R (2016) Ossiculoplastyin chronic otitis media: surgical results and prognostic factors of surgical success. Acta Otorrinolaringol Esp 68: 131-137.

6. Blom EF, Gunning MN, Kleinrensink NJ, Lokin AS, Bruijnzeel H, et al. (2015) Influence of ossicular chain damage on hearing after chronic otitis media and cholesteatoma surgery: a systematic review and metaanalysis. JAMA Otolaryngol Head Neck Surg 141: 974-982.

7. Yung MW (2003) Literature review of alloplastic materials in ossiculoplasty. J Laryngol Otol 117: 431-436.

8. Kartush JM (1994) Ossicular chain construction. Otolaryngol Clin North Am 27: 689-715.

9. Emir H, Kizilkaya Kaptan Z, Göcmen H, Uzunkulaoglu H, TuzunerA, et al. (2009) Ossiculoplasty with intact stapes: analysisof hearing results according to the middle ear risk index. Acta Otolaryngol 129: 1088-1094.

10. OConnell BP, Rizk HG, Hutchinson T, Nguyen SA, Lambert PR (2016) Long-term outcomes of titanium ossiculoplasty in chronic otitismedia. Otolaryngol Head Neck Surg 154: 1084-1092.

11. Martin A, Harner S (2004) Ossicular reconstruction with titanium prosthesis. Laryngoscope 114(1): 61-64.

12. Brackmann DE (1993) Tympanoplasty with mastoidectomy: canal wall up procedures. Am J Otol 14(4): 380-382.

13. Yung M, Vowler SL (2006) Long-term results in ossiculoplasty: an analysis of prognostic factors. Otol Neurotol 27: 874-881.

14. Fayad JN, Ursick J, Brackmann DE, Friedman RA (2014) Total ossiculoplasty: short- and long-term results using a titanium prosthesis with footplate shoe. Otol Neurotol 35(1): 108-113.

15. Bared A, Angeli SI (2010) Malleus handle: determinant of success in ossiculoplasty. Am J Otolaryngol 31: 235-240.

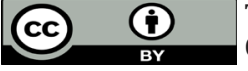

This work is licensed under Creative Commons Attribution 4.0 License

To Submit Your Article Click Here: Submit Article

DOI: $10.32474 /$ SJO.2020.05.000215

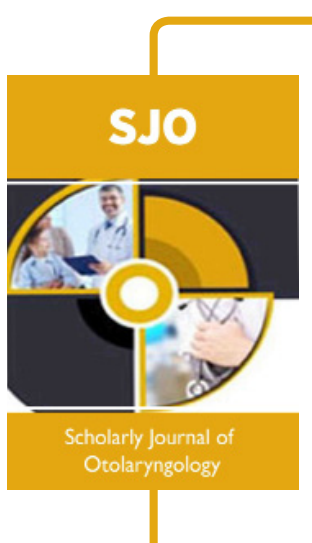

Scholarly Journal of Otolaryngology

\section{Assets of Publishing with us}

- Global archiving of articles

- Immediate, unrestricted online access

- Rigorous Peer Review Process

- Authors Retain Copyrights

- Unique DOI for all articles 